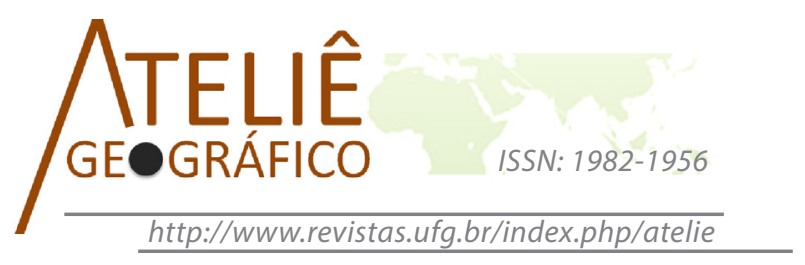

\title{
Reconfiguración socioterritorial resultado de la política turística en Tlayacapan, Morelos
}

\author{
Reconfiguration socioterritorial result of tourism policy in \\ Tlayacapan, Morelos
}

Résultat socioterritoriales Reconfiguration de la politique
du tourisme dans Tlayacapan, Morelos

María Mayela Benavides Cortés

Universidad Autónoma del Estado de Hidalgo

mayela.benavides@gmail.com

\begin{abstract}
Resumen
En México los procesos de turistificación $\mathrm{s}$ on $\mathrm{p}$ romovidos d esde 1 a política pública a través de los diferentes planes de desarrollo y turísticos, elaborados por los diferentes niveles de gobiernos. Promueven y presentan el turismo como una actividad que proporciona desarrollo económico, y bajo esta premisa los gobiernos conceden libertad a los inversionistas turísticos sobre el territorio y la cultura, bienes tangibles e intangibles considerados atractivos al turismo. Con el objetivo evaluarlas se estudió la gestión realizada en Tlayacapan para declararlo Pueblo Mágico y se utilizó una metodología cualitativa basada en entrevistas analizadas estructuralmente para conocer la memoria de los actores locales respecto a las dinámicas sociales históricas en la localidad contraponiéndolas con las actuales, así como los procesos territoriales que contribuyen a la apropiación y exclusión del espacio local a los actores originarios. En este estudio se estableció que la política turística para el pueblo no fue adecuada porque contribuyo a una reconfiguración negativa del territorio. Tanto por el incremento de vehículos, basura y bares, como por la falta de participación social en las políticas. Aspectos en detrimento de los locales, sus ocupaciones y dinámicas socioterritoriales.
\end{abstract}

Palabras clave: reconfiguración socioterritorial, política turística, Tlayacapan, Pueblos Mágicos.

\footnotetext{
Abstract

In Mexico touristification processes are promoted by public policy through different plans for tourism development and developed by the different levels of governments. Promote and present tourism as an activity that provides economic development, and under this premise government's grant to tourism investors on the territory and
} 
culture, tangible and intangible goods considered attractive tourism freedom. In order evaluate the management carried out in Tlayacapan to declare Magic Town and a qualitative methodology based on interviews analyzed structurally to know the memory of local actors regarding the historical social dynamics in the counterpose locality with current used was studied as well as territorial processes that contribute to the appropriation and exclusion of local space to the original actors. This study established that tourism policy for the people was not suitable because I contribute to a negative reconfiguration of the territory. Thus increasing vehicles, garbage and bars, and the lack of social participation. Aspects to the detriment of local, their occupations and socio-territorial dynamics.

Keywords: socioterritorial reconfiguration, tourism policy, Tlayacapan, Magic Town.

\begin{abstract}
Résumé
$\mathrm{Au}$ Mexique processus de touristification sont promus par les politiques publiques par le biais des plans différents pour le développement du tourisme et développés par les différents niveaux de gouvernements. Promouvoir et le tourisme présente comme une activité qui fournit le développement économique, et Sous cette prémisse les gouvernements accordent aux investisseurs du tourisme sur le territoire et la culture, les biens corporels et incorporels considérés comme la liberté touristique attrayante. Afin d'évaluer la gestion effectuée en Tlayacapan à déclarer magique ville et une méthodologie qualitative basée sur des entretiens analysés structurellement à connaître la mémoire des acteurs locaux en ce qui concerne les dynamiques sociales historiques dans la localité avec contraponiéndolas courant utilisé a été étudiée ainsi que processus territoriaux qui contribuent à l'appropriation et à l'exclusion de l'espace local pour les acteurs originaux. Cette étude a établi que la politique du tourisme pour le peuple ne convenait pas parce que je contribue à une reconfiguration négative du territoire. Ainsi l'augmentation des véhicules, des ordures et des bars, et le manque de participation sociale dans la politique. Aspects au détriment des locaux, leurs occupations et de la dynamique socio-territoriales.

Mots-clés: reconfiguration socioterritoriales, politique touristique, Tlayacapan, magique ville.
\end{abstract}

\title{
Introducción
}

En el año 2001, durante el gobierno del Presidente Fox, se creó el Programa Pueblos Mágicos, unos meses después se les otorgó la distinción de Pueblo Mágico a cuatro pueblos. Tlayacapan la recibió en el 2010, fue el número 42 en recibirla, en 2015 se les otorgó a 28 pueblos y de esta forma se llegó a 111 Pueblos Mágicos inscritos en el programa. Para que los pueblos puedan pertenecer a este, es necesario cumplan con los requisitos que el programa requiere, el primer criterio que establece es que la sociedad local en su conjunto o a través de una representación civil solicité su incorporación al programa ante las autoridades estatales y/o federales. Este condición es primordial, los locales o la representación acceden a cumplirlos porque se les presentan elementos positivos que repercutirán en su bienestar cuando reciban la distinción. Desafortunadamente en el caso de Tlayacapan, como de otros Pueblos Mágicos son escasos o nulos los beneficios que reciben a cambio de varios o numerosos perjuicios. Aspectos que las evaluaciones que realizan los gobiernos no alcanzan a distinguirlas, o a solucionar las problemáticas que surgen o se recrudecen por pertenecer al programa. 
En trabajos anteriores de algunos Pueblos Mágicos, se constató como el tener la distinción mejoró algunos aspectos sociales y territoriales entre otros, pero otros fueron afectados negativamente. En el caso se Santiago aunque el Gobierno Estatal y Municipal y el Comité de Pueblos Mágicos han realizado gestiones loables, el acondicionamiento del espacio público modificó el existente en el imaginario de los locales, algunos de ellos cuestionan el criterio en la aplicación de los recursos federales para mejorar la imagen del pueblo. La inseguridad que se desató en el poblado con el asesinato de su alcalde en el 2009 y que fue controlada hasta el 2013, no tiene relación con ser Pueblo Mágico, pero la distinción no fue suficiente para blindar un pueblo, a raíz de la violencia el turismo decayó y las dinámicas sociales históricas se ausentaron del espacio social por el toque de queda autoimpuesto por la población.

En el Pueblo Mágico de Palizada, algunas de las adecuaciones que se realizaron en el espacio social o no son las convenientes o no corresponden con el imaginario de los locales, como fue la sustitución de un pavimento en perfecto estado por uno de concreto hidráulico estampado de menor calidad elaborado por mano de obra foránea, acción que causa desconcierto en la población porque ellos conocen las necesidades en su pueblo, entre ellas la activación económica, dado que existe la urgencia de crear fuentes de empleo para los residentes. Otro ejemplo es el Pueblo Mágico de Mexcaltitán, las autoridades en aras de obtener la distinción, instruyeron a los isleños como debían arreglar sus casas, cambiar el color de las fachadas blancas por colores vistosos, eliminar los árboles a los que estaba ligado su imaginario e identidad. A lo anterior se añadió el cambio de acabado en las calles, de piedras y tierra por concreto estampado que provocó que aumentarán las ya altas temperaturas existentes, así como que las inundaciones fueran más severas. A tal grado llegó la incomodidad de los lugareños que recibieron con beneplácito la pérdida del título en 2009 y no volvieron a realizar gestiones para obtenerla por segunda vez.

Estudios realizados anteriormente en lugares que son transformados con el propósito de posicionarlos turísticamente, estas impactan negativamente a los residentes porque la reconfiguración territorial afecta las dinámicas sociales históricas, dado que el espacio es el escenario social donde se desarrollan. Basado en lo expresado se planteó que Tlayacapan para llegar a ser Pueblo Mágico sufrió varios tipos de modificaciones que reconfiguraron tanto su territorio y con ello las dinámicas y costumbres sociales conformantes de su imaginario.

Con la finalidad de resolver la interrogante planteada en la hipótesis se realizó una revisión teórico metodológica fundamentada en aspectos antropológicos del turismo que tratan las consecuencias de las modificaciones a los escenarios y las consecuencias para los locales, los autores estudiados fueron Delgado, Lagunas, Simonnica y Pearce. En los dos siguientes apartados se presentó brevemente el escenario de Tlayacapan, para posteriormente ilustrar el mapa de actores sociales que se desenvuelven en el Pueblo Mágico, entre los que están lo originarios, otros dos grupos a los que ellos llaman los de Nacatongo y los que consideran la elite, a los primeros los cuestionan de forma negativa y a los segundos les reconocen sus buenas prácticas culturales y ambientales. También se incluyó en el mapa a los diferentes niveles de gobierno. 
Además se expusieron los objetivos principales de los planes de gobierno instrumentados con el objetivo de postular al Programa de Pueblos Mágicos a Tlayacapan. Posteriormente se presentaron las apreciaciones de los originarios con referencia a las acciones ejecutadas por la administración municipal, refiriendo los beneficios y perjuicios para ellos por las acciones efectuadas. Así mismo se mostró la retrospectiva que la población articula sobre su pueblo, basada en los aspectos que guardan en su memoria de lo que fue, contrastando el lugar que habitan. Para complementar el panorama tanto de Tlayacapan como de los actores que residen en el pueblo, se estudió la perspectiva de los originarios con respecto a los otros dos grandes grupos de protagonistas, la elite y los de Nacatongo, en cuanto a la manera en que reconfiguraron el pueblo con las tipografías de sus viviendas. Por último se expusieron las problemáticas expresadas por los originarios están relacionadas el incremento en el número de turistas, la inseguridad, el aumento del tráfico vehicular en las estrechas calles, así como la venta y consumo de alcohol, así como la basura. Finalizando con las conclusiones en donde ante una política turística fallida, se incluyeron algunas recomendaciones.

\section{Cuestiones teóricas metodológicas consideradas}

Las localidades para que sean más atractivas para el turismo se les practica 'maquillaje' o hasta una cirugía estética, se realizan no sólo para hacerlas más atrayentes y consumibles, sino también para ocultar la realidad social existente que llega a ser complicada y con frecuencia no agradable para los incipientes poblados. Es evidente que estas estrategias se concibieron sin interés en beneficiar a la localidad o concediéndoles menor importancia a la otorgada al paisaje creado para satisfacer al turista (DELGADO, 2007, p.98).

La infraestructura para albergar y atraer al turismo conlleva cumplir con ciertas premisas, según Delgado (2007, p.94) “...es un tipo de industria cuya ficción es la de proporcionar el cumplimiento de los sueños...". Implica transformar el territorio creando una escenografía que resulte satisfactoria para las expectativas de los turistas. Inadecuadamente, este escenario en la mayoría de las ocasiones es un producto de la presión del tiempo sobre el espacio donde, tampoco es relevante su permanencia en el tiempo que en muchas ocasiones es efímera territorial y socioculturalmente.

Conforme una localidad sufre transformaciones para dar cabida al turismo los residentes locales cambian su percepción del lugar donde viven, ellos mismos llegan a convertirse en turistas del espacio que habitan porque consumen el nuevo escenario y la misma escenografía creada para albergar el turismo (LAGUNAS, 2007, p.21). Esto porque se crea una tramoya que frecuentemente no está relacionada con el paisaje preexistente, el cual se pierde y deja de existir, por lo tanto ya no se puede acceder a él, solo existe el recuerdo, por lo que la población queda privada del que fuera su hogar y solo pueden experimentan el nuevo espacio, el que se les impone en aras del progreso.

El impacto que el turismo tiene en el espacio produce modificaciones en la estructuración del territorio y soporta implicaciones sociales relevantes porque es en este donde tiene su inscripción la actividad humana. La ocupación turística es una de las 
dinámicas económicas que hace más vulnerable a un territorio, cualquier asentamiento que recibe turistas su fisonomía cambia para ajustarse a los requerimientos del turismo. Los efectos de este no quedan confinados al territorio destinado para ello. Tanto los actores locales, como sus ocupaciones, sus dinámicas sociales, aun sus tradiciones son trastocadas por el turismo.

La alteración al paisaje para convertir las ciudades en escenarios turísticos es una restricción que experimentan los residentes, los cambios contribuyen a que la población local mire la localidad con otra actitud mental a través de un nuevo imaginario y una actitud producida por la turistificación, que es resultado de consumir el nuevo producto creado para ser vendido al turista, así como el nuevo ambiente que se percibe y respira en el lugar (SIMMONICA, 2007, p.21). Pearce (1988, p.80, 81) cuando habló del turista y del habitante local estableció que entre mayor sea la diferencia socioeconómica entre ambos mayor es el impacto social para los locales.

\section{El escenario de Tlayacapan}

Tlayacapan, Pueblo Mágico ubicado en el Estado de Morelos, rodeado de montañas y con atractivo cultural, frecuentado en su mayoría por quienes radican en la Zona Metropolitana del Valle de México. El reconocimiento internacional de mayor envergadura al que puede aspirar un sitio es el que otorga la UNESCO con el título de Patrimonio de la Humanidad, en 1996 el ex convento de San Juan Bautista del siglo XIV de Tlayacapan junto con otros trece conventos les fue otorgada tal distinción por ser los primeros monasterios de las faldas del Volcán Popocatépetl ${ }^{1}$. El poblado es uno de los lugares privilegiados de Morelos por su arquitectura de adobe, festividades, tradiciones, cultura, y esplendoroso paisaje, rodeado de montañas, atributos que sirvieron de fundamento para proponer a Tlayacapan como Pueblo Mágico, distinción que le fue otorgada el 7 de julio de 2011.

Hace casi cinco décadas Tlayacapan por sus atractivos y emplazamiento paisajístico, fue elegido para filmar locaciones de importantes películas norteamericanas y nacionales, como son: Butch Cassidy en 1969 y Dos Mulas para la Hermana Sara en 1970, así como la película mexicana La Valentina en 1966. Los filmes promovieron y mostraron la belleza de Tlayacapan. En el 2006 se grabó el video de la pieza musical When you were Young, en cual se puede apreciar vista aéreas del pueblo como interiores de algunas de sus edificaciones.

\section{Actores sociales en el escenario de Tlayacapan}

En el estudio de la localidad de Tlayacapan se distinguieron varios grupos de actores, uno es el de los locales asentados por generaciones en el poblado, considerados por el Gobierno del Estado de Morelos como gente consciente, respetuosa y orgullosa

1. Los monasterios están ubicados en las localidades de Atlatlahucan, Cuernavaca, Tetela del Volcán, Yautepec, Ocuituco, Oaxtepec, Tepoztlán, Tlayacapan, Totolapan, Yecapixtla y Zacualpan de Amilpas, en Morelos y tres de Puebla se encuentran en Calpan, Huejotzingo y Tochimilco 
de ser tlayacapense, de la cual busca adquiera una educación y cultura turística bajo una concientización de lo que es su patrimonio, que estén orgullosos de él y que lo preserven, así como lo que representa este para la localidad. Los locales se consideran a sí mismos como gente amable y confiable que contribuye a que el pueblo sea un sitio seguro. Tienen una fuerte identidad basada en quienes somos nosotros, orgullosos de lo que fue su tierra, sus tradiciones y bello paisaje.

Los otros son los de Guerrero atraídos por los trabajos en el campo y en la construcción, considerados por los nosotros como indeseables porque los ven como personas malas, de algunos piensan que dejaron su lugar natal por conductas antisociales, los creen borrachos y drogadictos. Ellos son quienes aprovechan los apoyos económicos otorgados por los programas municipales aunque no contribuyen al cuidado del ambiente. Viven en Nacatongo, zona considerada de escaso valor por las características pedregosas del suelo, con una imagen urbana deteriorada por el tipo de construcciones efectuadas por sus habitantes. Los nosotros dicen que el nombre de la zona describe a sus residentes.

Otros son los que llegaron a residir fascinados por la localidad, viven en la periferia de la zona central, algunos lo hacen de forma permanente, estos pueden ser nacionales o extranjeros, mayormente europeos, otros tienen casas de segunda residencia, en su mayoría son capitalinos. Ellos construyen quintas en grandes terrenos que compran en conjunto para obtener un mejor precio. Son gente buena que cuidan el ambiente construyendo viviendas autosustentables. Los nosotros los consideran la elite contrastando fuertemente con la percepción que tienen de los guerrerenses.

En otro plano está el Gobierno Federal, Estatal y Municipal, el primero creó el Programa Pueblos Mágicos, el cual contempla lineamientos que deben ser observados por quienes aspiran a tal distinción, quienes la obtienen son beneficiados con recursos federales para el embellecimiento del poblado. El segundo provee de lineamientos por medio de planes y reglamentos que faciliten la adscripción de la localidad al programa. El Gobierno Municipal instrumenta los planes, ejecuta los programas, las obras y los eventos convenientes para realzar el pueblo y sea un sitio atractivo y atrayente para el turismo.

\section{Planes de gobierno para Tlayacapan}

El 7 de julio de2010 el Gobierno del Estado de Morelos publicó en el Periódico Oficial "Tierra y Libertad" dos reglamentos y dos planes para Tlayacapan, con la finalidad de realizar los ajustes jurídicos y las adecuaciones administrativas y físicas para que esta localidad fuera reconocida como Pueblo Mágico. Los instrumentos que debía observar el Ayuntamiento de Tlayacapan fueron: Plan Estratégico de Desarrollo Turístico, Reglamento para la Protección, Mejoramiento y Conservación de la Imagen Urbana, del Patrimonio Cultural y Anuncios del Municipio de Tlayacapan, Morelos, Plan de Manejo en función del Programa Pueblos Mágicos y Reglamento para la Regulación del Comercio Ambulante y Semi Fijo en el Municipio de Tlayacapan, Morelos.

Se considera que los programas gubernamentales que tienen mayor relación con el impulso del turismo en la localidad son los dos planes. Los objetivos del Plan de 
Manejo en función del Programa de Pueblos Mágicos fue desarrollado teniendo en cuenta el programa federal mencionado, el cual debe ser observado para ser reconocido como uno de ellos. Los objetivos tienen como propósito atender y dar solución a los aspectos cruciales para el progreso favorable de la actividad turística. La meta principal fue articular las estrategias necesarias para brindar servicios públicos cuantitativos y cualitativos para la atención al turista, la general fue derivada en seis objetivos específicos, desarrollar acciones concretas para el manejo adecuado de los desechos sólidos originados por el turismo; crear nuevas opciones para brindar atención e información al turista; desarrollar programas de educación turística en las escuelas de la localidad en todos sus niveles, concientizar a la población sobre la importancia de lograr una cultura turística, lograr un equilibrio entre medio ambiente y economía, para consolidar un desarrollo sustentable en la localidad, desarrollar acciones de promoción y difusión del pueblo de Tlayacapan a nivel nacional e internacional y mejorar la imagen urbana del pueblo ${ }^{2}$.

\section{Apreciaciones de los originarios a la política pública municipal}

Las dos últimas administraciones municipales de Tlayacapan, la de 2009 a 2012 y la de 2012 a 2015 realizaron modificaciones al poblado, la primera con la intención de lograr la distinción de Pueblo Mágico, la segunda para conservar una imagen urbana adecuada. La gran mayoría de los actores locales cuestionan diferentes aspectos de las gestiones, como son la malversación de fondos, intervenciones inadecuadas, tratamiento del espacio público, así como las afectaciones a los agricultores. Con respecto a los cambios con la finalidad de atraer al turismo la autorización de un gran número de establecimientos de micheladas, así como el aumento de la cantidad de basura resultante de la actividad.

Los residentes lamentan que el presupuesto federal que recibió el ayuntamiento por ser Pueblo Mágico, no se haya empleado en su totalidad en mejorar las condiciones del poblado, y que lo utilizado no haya sido de forma adecuada. Hacen una comparación del pueblo contiguo que no obtuvo tal distinción, razón por la que no tuvo las finanzas federales, y aun así cuenta con un equipamiento urbano superior.

Llegan algunas remesas del Gobierno Federal...falta administración adecuada, hay algunos pueblos que les dan lo mismo y lo ocupan en lo que debe ser, por ejemplo Atlatlahucan $^{3}$ es un pueblo que ha ocupado bien su dinero, no es Pueblo Mágico, en Morelos solo hay dos, Tepoztlán y Tlayacapan. Ahí hay un error, no sé cómo se lo dieron a Tlayacapan, Atlatlahucan está pintado de un solo color sus casas, de iluminación es todo lo mismo. Lo segundo es que tiene una fuente mágica dentro de la población, con

2. Periódico Oficial Tierra y Libertad, Ayuntamiento de Tlayacapan, Morelos, Plan de Manejo en función del Programa Pueblos Mágicos. Periódico Oficial "Tierra y Libertad" 7 de julio de 2010, 6 a Época \# 4817 DE consultado el 13.05.15 http://periodico.morelos.gob.mx/periodicos/2010/4817_2A.pdf

3. Entre Tlayacapan y Atlatlahucan existe tan solo una distancia de 12 kilómetros que pueden ser recorridos en un promedio de veinte minutos. El número de habitantes en el 2010 en Tlayacapan fue de 14467 habitantes, mientras en Atlatlahucan fue de 13863. El ex convento de San Mateo Apóstol ubicado en Atlatlahucan, al igual que el ex convento de San Juan Bautista en Tlayacapan, son parte de los once ex monasterios que cuentan con la declaratoria de Patrimonio de la Humanidad en 1996. 
música, entonces dan varias funciones a partir de las ocho de la noche, la verdad es que dejan maravillados a las personas que asisten...entonces no sé qué hacen los acaldes a nivel nacional que van a Europa, a Suiza a gastarse el dinero... a su pueblo lo siguen teniendo igual. A nivel nacional depende mucho la administración, que el dinero se utilice en lo que debe de ser, no para sus bolsos. Suben al poder y se quedan con parte del dinero, la bolsa, quien es el culpable, a lo mejor nosotros mismos que no les insistimos, que los dejamos hacer lo que quieran...Este pueblo no tiene agallas para reclamar sus derechos, somos muy agachones de veras, no tenemos esa capacidad de concientizarnos unos a otros...

Los tlayacapenses creen que la administración local de 2009-2012 no capitalizó los recursos de forma óptima, la actual está a tiempo de enmendar el camino, si destina las finanzas públicas a mejorar la imagen urbana con la intervención de los espacios públicos de Tlayacapan en tres rubros que son básicos para que los residentes vivan con calidad. El primero es que las calles del pueblo se arreglen con pavimentos de calidad para que estén en buenas condiciones, y que estas mismas cuenten con la iluminación adecuada para que puedan transitar con seguridad por ellas. Otro aspecto fundamental es que no exista basura en la vía pública.

Yo creo que hubo oportunidad de cambiar un poquito este pueblo...han desaprovechado mucho. El anterior ayuntamiento tuvo oportunidades de hacerlo, este ayuntamiento le está echando ganas, pero creo que le va a costar trabajo, lo más feo es que habido oportunidades de que todo sea diferente pero no se han aprovechado, no sé porque razones, pero no se aprovechan...con los recursos debieron pavimentar las calles... hay mucha basura por donde quiera. Alumbrado público si hace falta, no es tan completo, hay algunas calles que están muy obscuras, algunas son principales y están bien feas...Yo creo que fue el ayuntamiento que empezó a dejar lo de las micheladas, a vender permisos... ${ }^{4}$

Si viene mucho turista... pero creo que antes venía más gente, lo que me molesta es tanto borracho, tanta basura...

En aras de mejorar la imagen urbana de Tlayacapan el ayuntamiento intervino el centro de la localidad. Los residentes consideran que las obras como la inversión que se realizó en el espacio público no les benefició, más bien les perjudicaron. Se identificaban con el que formó su imaginario, el que estaba ligado a su vida cotidiana y donde expresaban diferentes dinámicas sociales como sentarse a platicar en las bancas existentes o donde los niños jugaban. Lamentablemente la nueva fuente no funciona, así como el reloj que adorna el palacio municipal. Mágico para ellos está relacionado con la desaparición de recursos, pero también con la pérdida del paisaje que les fue cotidiano.

Muchos bromean con eso, porque dicen que lo mágico es que se desaparecen los recursos.......en realidad yo no he visto gran avance con el nombramiento de Pueblo Mágico...se remodeló El Jacalón y el centro, pero creo que fue peor, antes me gustaba más...Pues era una explanada, no tenía nada, pues la

4. Entrevista realizada en agosto de 2013 a mujer de 22 años originaria de Tlayacapan.

5. Entrevista realizada en agosto de 2013 a mujer de 25 años originaria de Cuautla, 8 años de residencia 
gente iba a sentarse en las banquitas.......ahora con la fuente digo que fue un dinero mal invertido......los árboles que sembraron ahí están todos secos....no precisamente el de antes, sino algo mejor, algunos juegos para los niños, más bancas, un kiosco...6

Quienes se dedican a la agricultura creen que en su pueblo antes de que fuera Pueblo Mágico, tenían mayores apoyos para la siembra, estos disminuyeron considerablemente cuando el sitio pasó de rural a turístico, los subsidios con la intención de fortalecer la agricultura fueron reducidos, mientras para los campesinos de pueblos circunvecinos no disminuyó la ayuda. En Tlayacapan existe un mayor número de personas que viven del campo que del turismo, además estas tierras son propicias para ello. Razón por la que no se debe tomar a la ligera que una actividad terciaria desplace a una primaria.

Creo que nos afecta al campesino, ya no habido apoyo, cómo ya no es zona marginada, ya afecta algo, recortan presupuestos, por ejemplo un mototractor en otros lado dan el $70 \%$, a nosotros nos da el gobierno $50 \%$, tenemos que poner más, nos afecta. Este año nos ayudó el gobierno, ahora que se amolaron las plantas. Desde que es Pueblo Mágico, ya no es zona marginada ${ }^{7}$.
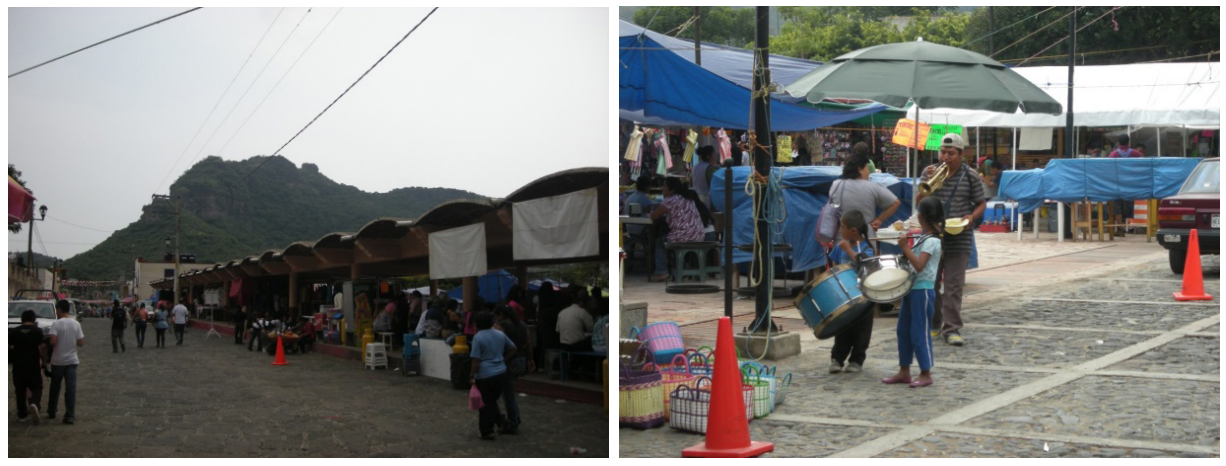

Espacios públicos del centro de Tlayacapan (2013, Benavides).

\section{La mirada retrospectiva de los originarios sobre Tlayacapan}

Se estudió el discurso de los habitantes de Tlayacapan en varios sentidos, el imaginario que ellos conservan de las condiciones rurales del poblado hace medio siglo, así como las que tienen del poblado actual. Su apreciación del desempeño de la administración pública en cuanto a las intervenciones realizadas al pueblo. Las implicaciones y el significado de mágico basado en sus vivencias recientes. Además se dio un espacio para analizar las dinámicas socioculturales en función de la reconfiguración socioterritorial, así como las problemáticas actuales derivadas de ella.

6. Entrevista realizada en agosto de 2013 a mujer de 22 años originaria de Tlayacapan.

7. Entrevista realizada en agosto de 2013 a dos hombres de 30 y 38 años originarios de Tlayacapan. 
Hace seis décadas Tlayacapan fue un lugar rural olvidado, la modernidad no lo había transformado, las calles estaban empedradas, y en las uniones de tierra crecía el pasto, por lo que el agua de lluvia se filtraba al subsuelo, era un lugar más fresco. Las casas eran de adobe, en la actualidad por ser más rápido y económico la mayoría de las casas son construidas con block o tabique. No había servicios públicos, los habitantes aprovechaban los recursos naturales para proveerse del agua indispensable para vivir. Primero la extraían de los jagüeyes, algunos todavía existen pero no cuentan con la misma cantidad de agua que en el pasado. Los residentes tienen presente que el pozo de la plaza fue clausurado y la fuente ornamental que fue instalada en ella hace unos pocos años ni siquiera funciona.

Estaba muy atrasado, mucho tecorral, muchos tecorrales ${ }^{8}$ en esta calle de aquí a abajo...ya todo se llenó de casas...todo estaba más tranquilo, más limpio, no teníamos agua, íbamos a traerla a los jagüeyes. Nos bañábamos cada ocho días y no andábamos puercos, por lo mismo que no había tanta basura como ahora... No teníamos luz, no teníamos agua, pues con puro quinqué. Con bombilla la colgábamos en la pared, ni pensábamos en la luz. Cuando entró la luz parecía cine, una persona tenía tele y pagábamos veinte centavos por ir a ver la tele... pero la gente andaba a gusto, poco a poco fuimos teniendo, entre más tenemos más queremos...Tuvimos una fuente de agua en la plaza, de la potable y allá íbamos a traer con botes, colas que se hacían de aquí, ya se pudo tener en la casa, entre más cerca está...más cerca la queremos...ya la pusimos en el lavadero... ${ }^{9}$

El Plan de Manejo elaborado por el gobierno con la finalidad de que Tlayacapan llegará a ser Pueblo Mágico contempla la eficaz recolección y reciclamiento de la basura. Los habitantes asocian el incremento de la cantidad de basura con el aumento de turistas, y la califican negativamente como contaminación. Pero también hay quien añora los tiempos en que ni siquiera usaban bolsas de plástico, las cuales contribuyen al aumento de basura.

Antes era bien bonito las mujeres iban a traer el pan en un plato, nada de nylon como ahora, por eso había limpieza. Ahora mucha basura, por eso ha cambiado muchísimo por la basura... hay muchos cambios, pero basura es lo que sobra... ${ }^{10}$

Hace unas décadas los locales dependían económicamente del campo, la modernidad, las vías de comunicación y transporte aunado al turismo contribuyen a que existan otras fuentes de empleo, la imagen de los campesinos en las esquinas sin trabajo quedo en el imaginario de los adultos mayores.

Antes no había tanto trabajo, solo en el campo, se acababa cuando se despachaba la milpa. La gente andaba sentándose en las esquinas porque no había que hacer. Cuando sembrábamos jitomates ya todo el tiempo había trabajo... aquí

8. El tecorral es un muro pequeño elaborado con rocas apiladas sin ninguna clase de cemento o argamasa entre ellas generalmente tiene un metro de altura por aproximadamente cincuenta centímetros de ancho.

9. Entrevista realizada en agosto de 2013 a hombre de 69 años originario de Tlayacapan.

10. Ibid 
en la esquina...el 15 de agosto era el último día, se despachaba la milpa, y a sentarse en las esquinas, no había nada de verás...Mucha gente salía de acá para ir a buscar trabajo en las cañas... Me gusta que ahora el trabajo sobra ${ }^{11}$.

Los tlayacapenses tienen servicios públicos y más opciones de empleo que en el pasado, perdieron un lugar tranquilo y limpio, por donde caminaban sin problemas.

\section{Los otros: la elite y los de Nacatongo}

En la periferia del pueblo se localizan residencias construidas con adobe y teja, rodeadas de grandes árboles y jardines. En la mayoría de ellas viven extranjeros o personas de la ciudad de México, los primeros son quienes más las usan como residencia permanente y los segundos en mayor medida como segunda residencia. Los locales reconocen que en esa zona es donde viven intelectuales, políticos y personajes de la farándula. Que las condiciones de la zona son mejores que las del resto del poblado, aun del mismo centro, además construyen con materiales tradicionales, mientras donde viven los oriundos lo hacen con block y tabique por resultar de menor costo. La elite realiza fuertes inversiones para que sus residencias cuenten con tecnología de vanguardia para el cuidado del ambiente.

San Lorenzo, de la barranca para allá es otro tipo de vida, lo más "nice" que hay aquí en Tlayacapan "High Society", es más caro, es más sólido, la gente de provincia les gusta las orillas. Es más sólido porque es tranquilo, no hay tanto tráfico... ique caseronesi También vive gente de Tlayacapan. Ahora vienen a comprar, compran muy barato porque ellos no compran doscientos metros, compran de cinco mil en adelante, al comprar esos cinco mil le castigan mucho el precio al propietario, se obliga a vender por necesidad...cuando lo declararon Pueblo Mágico, antes estaba más barato, ahora está muy caro. Ya después de eso hacen como tipo sociedad y compran esos 5000 metros para tres o cuatro personas. Hacen unos caserones hermosísimos y con un sistema de iluminación fabuloso, no estás en otro lado, estás en Tlayacapan. No hace mucho tiempo me fije en una casa de San Lorenzo que tiene celdas solares. Tienen un sistema de vida adecuado a sus posibilidades, son más ecológicas tienen calentadores solares, de hecho el agua la reciclan, son más conscientes... Aquí estamos al revés de Tepoztlán, a la gente nativa de Tepoz la sacan a las orillas. ${ }^{12}$

Los originarios venden sus tierras, se desprenden de su patrimonio y herencia, sitios donde podrían vivir su descendencia si las conservaran. Buscan solucionar el presente, mejorar sus condiciones actuales de vida, comprometiendo su futuro. La dinero obtenido de la venta de lo suyo no les permite tener una casa como la que se construyen en lo que ya no les pertenece, esto principalmente porque lo recibido no es suficiente y porque no poseen los recursos socioculturales para tomar este tipo de decisiones.

Los de Nacatongo en su mayoría son de Guerrero, no son valorados y apreciados por los locales, viven en una zona de poco valor por las condiciones topográficas, ellos

11. Ibid

12. Entrevista realizada en agosto de 2013 a mujer de 60 años originaria de Tlayacapan. 
asocian la inseguridad y los robos con los fuereños. Los originarios consideran que ellos son quienes aprovechan los apoyos que otorga el gobierno. A lo expresado se añade que no cuidan el agua porque no les importa dado que no cuentan con una consciencia ambiental.
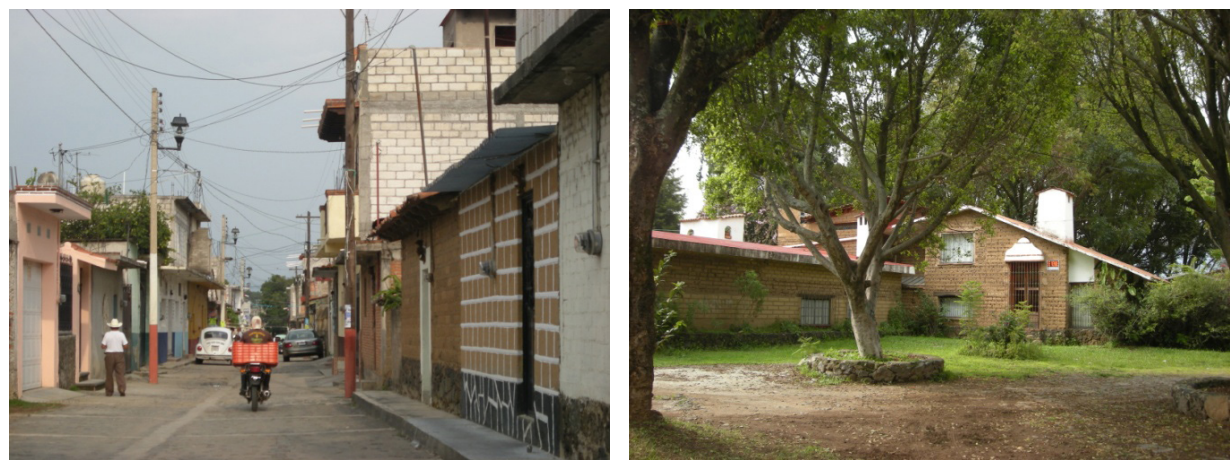

Calle de Tlayacapan, nuevas viviendas de block. Paraje de San Lorenzo, vivienda de sillar y teja (2013, Benavides).

Dos hombres de Guerrero con poco tiempo en Tlayacapan narraron su experiencia en el poblado, resaltaron que las condiciones laborales son mejores en su tierra que las que han encontrado en el pueblo. Sabiendo que no son apreciados por los locales, hablan de que son buenas personas sin interés de causar problemas.

Nos sentamos en la plaza, un día cae un señor que quiere peones, otro día cae otro y así...no tenemos trabajo fijo...nos queremos regresar la verdad nos pagan poco...en Guerrero hay mucho trabajo en las pizcas de mazorcas...nosotros somos pacíficos respetamos a la gente mayor y a la juventud también... ${ }^{13}$

Los actores mencionados son ubicados y reconocidos por los locales tanto en la ocupación del territorio como en la forma en que modificaron las dinámicas sociales preexistentes, los locales los reconocen y los diferencian de ellos, saben quiénes son los otros que cuentan con mayores recursos económicos y socioculturales que ellos y quiénes los otros que tienen menos que ellos.

\section{Las problemáticas del Pueblo Mágico}

Los principales problemas que afronta Tlayacapan en el 2015 es la inseguridad, la venta excesiva de alcohol, la falta de lugares de estacionamientos para los turistas y basura en grandes cantidades. De haber sido un lugar tranquilo, hoy es un pueblo donde los robos a casa habitación aumentaron, estos son mayormente en las casas de segunda residencia. Por esta razón el Gobernador de Estado instaló el Sistema de Mando único en

13. Entrevista realizada en agosto de 2013 a dos hombres de 39 y 22 años originarios de Arcelia, Guerrero. 
el poblado, decisión que fue rechazada por los habitantes ${ }^{14}$. A lo expresado se añade que la Secretaria de Turismo del Estado de Morelos declaró que en el carnaval de este año hubo venta indiscriminada de alcohol, por lo que la localidad estuvo a punto de perder su denominación de Pueblo Mágico ${ }^{15}$. El problema no se limita al carnaval sino es durante todo el año, a tal grado que los residentes dicen que es un pueblo de borrachos.

En los planes publicados en 2010 se proponían estrategias para afrontar el aumento de afluencia vehicular por la visita de turistas, así como el crecimiento de la cantidad de basura por la misma razón. Las tácticas no fueron aplicadas o no funcionaron, razón por la que los residentes expresan su descontento, así como su incomodidad por no poder caminar sin obstáculos por las calles centrales en los días que acude el turismo. A lo que se añade lo lastimoso que resulta ver a personas degradadas por el consumo de alcohol en la vía pública.

\section{Conclusiones}

Los beneficios para Tlayacapan por ser Pueblo Mágico son que la distinción contribuyó al aumento de los turistas y con ello a que crezcan y existan otras opciones de trabajo para los residentes. Con las finanzas otorgadas por el programa se mejoró la imagen de la localidad. Sin embargo los locales miran con recelo el desempeño de la administración municipal por las intervenciones urbanas realizadas con la finalidad de obtener la distinción. Las modificaciones efectuadas al espacio público central crearon un escenario destinado a atraer turistas, en la que los habitantes no fueron tomados en cuenta, lo que influye en que las que las evalúan como inadecuadas, no les agradan porque no corresponden con su imaginario, al no ser incluidos se sienten excluidos. Se aplicó maquillaje en el núcleo del poblado, con el objetivo de mejorar su apariencia, desafortunadamente las áreas circunvecinas con construcciones precarias no fueron consideradas en el proyecto.

Las alteraciones a las dinámicas sociales residen en la apropiación del pueblo tranquilo que fue solo para los locales, y actualmente en fines de semanas y periodos vacacionales, por la afluencia de turistas se convierte en un lugar caótico, por el congestionamiento de las calles y banquetas, así como basura en la vía pública. La permisividad en la apertura de bares de micheladas acrecentó el número de personas alcoholizadas en la vía pública. El resultado es una reconfiguración socioterritorial, por el cambio de la imagen del pueblo, la suplantación de los actores y sus actividades cotidianas.

A lo anterior se añade que los residentes no originarios afectan la percepción de seguridad de los locales, los de Guerrero son considerados como responsables de los robos que han ocurrido. Los de la elite por poseer un nivel de vida más alto que el de la

14. Nota periodística en Excélsior el 8 de mayo de 2015. Tonantzin, Pedro, Excélsior DE consultado el 08.05.15 http://www.excelsior.com.mx/nacional/2015/05/08/1023046

15. Nota periodística en Conurbados el 24 de febrero de 2015. Nava, María, Conurbados DE Consultada el 12.05.15 http://conurbados.com/2015/si-hubo-venta-indiscriminada-de-alcohol-durante-carnavales-enmorelos-secretaria-de-turismo/ 
población original, cuentan con mayor cantidad de bienes, lo que resulta atractivo para los ladrones. Los residentes no originarios, con perfiles socioculturales y económicos extremos y distantes de los oriundos, configuraron nuevas dinámicas y tipografías arquitectónicas en el pueblo.

En el diseño de los planes se contemplaron aspectos considerados cruciales como fue el aumento del aforo vehicular y de la basura tanto por el Gobierno del Estado de Morelos como por el Gobierno Municipal de Tlayacapan, lamentablemente su instrumentación no fue exitosa. Los gobiernos no manifestaron, ni consideraron en sus planes eliminar la posibilidad de que el pueblo se volviera atractivo por el incremento de bares, lo cual debieron tener en cuenta ante el antecedente del Pueblo Mágico de Tepoztlán, Morelos que obtuvo el nombramiento en el 2001 y lo perdió en el 2009 por el aumento en bares y consumo de alcohol, en el 2010 recuperó la distinción, localizado a tan solo 25 kilómetros de Tlayacapan.

Es conveniente que los gobiernos contabilicen sus aciertos y desaciertos, así como que involucren a los residentes para contar con un panorama completo de las problemáticas y soluciones. Tanto para que sus gestiones sean exitosas y amortigüen las secuelas del turismo, en lugar de incrementarlas. Es vital que los gobiernos a todos los niveles instrumenten políticas turísticas y en todos los rubros que sean inclusivas con la finalidad de que las reconfiguraciones socioterritoriales no resulten violentas para los residentes de las localidades turísticas.

\section{Referencias}

DELGADO, Manuel, "Ciudades sin ciudad. La tematización "cultural" de los centros urbanos" en Lagunas, David (coord), Antropología y turismo, México, Plaza y Valdés Editores, 2007, pp. 91-109.

LAGUNAS, David, 2007, Introducción, en Lagunas, David (coord.) Antropología y turismo, México, Plaza y Valdés Editores, 2007.

PEARCE, Douglas, Desarrollo turístico, su planificación y ubicación geográfica. Tr. Lilia Soriano Bello y Miguel Ángel Acerenza, México, Editorial Trillas, 1988.

SIMONICCA, Alessandro, Conflicto (s) e interpretación: problemas de la antropología del turismo en las sociedades complejas, en Lagunas, David (coord.), Antropología y turismo, México Plaza y Valdés Editores, 2007, pp. 27-45. 
María Mayela Benavides Cortés.

Doctora en Urbanismo y Maestra en Arquitectura por la Universidad Autónoma de México (UNAM) y graduada en Arquitectura por la Universidad Autónoma de Nuevo León (UANL). Actualmente realiza una estancia posdoctoral de El Colegio del Estado de Hidalgo, donde es investigadora y profesora de los posgrados que se imparten en la institución: Maestría en Planeación y Desarrollo Regional y Maestría en Desarrollo Urbano Regional. Calle Hidalgo 618, Colonia Centro, Pachuca, Hidalgo, México CP 42000.

E-mail: mbenavides@elcolegiodehidalgo.edu.mx,mayela.benavides@gmail.com.

Recebido para publicação em janeiro de 2017 Aprovado para publicação em abril de 2017 